the generally accepted view. After reviewing the conditions in which an increased blood pressure is generally regarded as responsible for the vascular lesion, he remarks that "the factor of increased content of metabolites in the blood is also involved," and he expresses the opinion that an increased blood pressure cannot be excluded from the etiology of arterio-sclerosis, and that "it is without doubt an accessory factor in the production of arterio-sclerosis provoked by other causes." For a full discussion of this subject reference should be made to Allbutt, Andrewes, Thorel, MacCallum, and Moschcowitz.

Whether, however, a degenerative or proliferative lesion results from the action of a toxin on the vessel wall, may depend on the one hand on the nature of the pathogenic agent. On the other hand, the power of resistance of vascular tissues to the pathogenic agent must be an important determining factor, and it is possible that whether diffuse hyperplastic sclerosis or senile arterio-sclerosis result depends rather on the vitality of the tissues affected than on the nature of the pathogenic agent. There is some evidence in farour of this view, and factors such as age and inheritance find their due place in the tangle of causation in the extent to which they undermine and modify the reaction of vascular tissues to insult. Thus there is no reason to believe that age in itself is the cause of arterio-sclerosis, and Ophüls ${ }^{22}$ has shown that the curve of incidence of arterio-sclerosis does not correspond with what would be expected if the lesion were the direct result of it and of the senile deterioration associated with it.

\section{Mönckeberg's Sclerosis.}

Mönckeberg's sclerosis illustrates this aspect of the problem from another point of view. The form of sclerosis that he describes is often included in the senile form of arterio-sclerosis; it does indeed often occur in old age, and it is like senile arterio-sclerosis in the fact that it is apparently a primary affection of the media and is characterized by calcification. In a sense it is more senile than senile arterio. sclerosis, for the intima often fails to proliferate, and when it occurs it is often late in the evolution of the lesion as a tardy process of repair. But it is not age that has weakened the vessel walls and prevented their reaction to insult-it is disease, not local but general; thus of the 12 pure cases described in Mönckeberg's original paper, 23 died of cancer, 4 died of phthisis, 1 of advanced morbus cordis, and 3 of cachexia due to chronic infection. I think it is here that diabetes mellitus sometimes finds its place in the etiology of arterio-sclerosis.

SUMmary.

The study of the pathology of arterio-sclerosis has impressed me with the vivid picture of reaction in tissues to insult, response to injury, and repair of damage done. Great students of pathology such as Virchow interpreted the lesion in terms of inflammation, Thoma in terms of involu. tione and Jores in terms of growth. These men, at least, have failed to grasp the cloven hoof of decadence and decay. It is asking too much to expect a restitutio ad integrum in arterio-sclerosis, and, as in tuberculosis of the lung, we may well be content with a lesion that heals by calcification and fibrosis. The prospect of recovery in vascular tissue is indeed better than it is in the parenchyma of the lung; new vessels are formed more easily than new. paren. chyma. Louis Gross ${ }^{24}$ has demonstrated the formation of new ressels in the kidney of renal sclerosis, and the rapidity of their formation is strikingly illustrated in thromboangeitis obliterans, where new ressels may be formed in the lumen of the affected artery before the original process of disease has subsided, so that the new ressels may themselves be affected by the original process of disease. Again, it is remarkable evidence of the healing power of vessels that aneurysm of the aorta is rarely due to arterio-sclerosis even when present in a severe degree. There is a big field for inquiry in clinical medicine where evidence of the healing of arterio-sclerosis may be collected, and yet before the gate into this field is opened the clinical diagnosis of arterio-sclerosis needs a closer approach.

As the problem of arterio-sclerosis is contained in its definition, I will end by stating the problem as I have tried to outline it :

Axterio-sclerosis is a lesion characterized by a pathological thickening of arterial coats, particularly of the intima; inflammatory reaction is of first importance; degenerative changes are an essential part of the picture; hyperplastic and involutionary processes play a part; no unit factor is responsible for its cauation. Its development in its extent and form depends on a balance between the action of toxic agents and the power of resistance of the vessel wall to their attack.

In conclusion, it is a real pleasure to acknowledge the help and advice that I have received from Sir Frederick Andrewes, and the constant assistance kindly given by Sir Bernard Spilsbury.

1 Evans, Geoffrey : Quart. Journ. Med., Oxford, 1921, 14, 215. ${ }^{2}$ Fishor, Theodore: Guy's Hosp. Reports, 1894, 51, 97. 'Oliver, George: Studies in Blood Pressure, third edition, 1916. 116. A Allbutt, Sir Clifford: Diseases of the Arteries and Angina Pectoris, 19i5. SMacCellum, W. G.: Physiol. Reviews, 1922, 2, 70. 6 Strouse and Kelman : Arch. Int. Med., 1923, 31, 151. 7 Moschcowitz, Fli: Journ. Amer. Med. As 800., 1922, 79, 1196:: 1905, 59, 319. 8 Shaw, H. Batty : Hyperpiesia and Hyperpiesis, Oxford Med. Pub., 1922. 9 Krogh, A.: Journ. Physiol., 1919, 52, 457. 10 Krogh, Harrop, and Rehberg: Ibid., 1922, 56, 179. 11 Evans, Geoffrey: Quart. Journ. Med.. Oxford, 1922, 16, 33. 12 Herxheimer, G.: Handb. d. Arztl. Erfahr. im Weltkriege, 1921, 8. ${ }^{13}$ Moore, R. Foster: Quart. Journ. Med. Oxford, 1916, 10, 30. 14 Dunn, John S.: BRrrish MEDTCAL JoURNAL, 1922, ii. 1166 , 15 Volhard and Fabr: Die Brightsche Krankheit, J. Bpringer, 1914. is Welch and Flexner: johns Hopkins Hosp. Bull. 1892, 3, 17. 17 Klotz, Oskar: Journ. Exp. Med. 1910, 12, 707. 18 Klotz and Manning: Journ. Path. and Pact.. 1911, 16, 21i. 19 Klotz, O.: Journ. Exp. Med., 1906, 8. 322. 20 Josue: Presse Med., 1903, 11, 798; O. R. Soc. de Biologie, 1905, 59, 319. 21 Thorel, C. : Lubarsch-Ostertag, $1915,1,182 .{ }^{22}$ Ophtils, William: Stanford Univ. Pub.
Med. Sci., 1921, 1, 5. 23 Mönckeberg, J. G.: Virohr.w's Archiv., 1903, 171, 141.

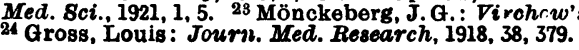

\section{ON ANKYLOSTOME INFESTATION : THE CHANGING PROBLEM.}

BY

CLAYTON LANE, M.D., LieUt.-CoL: I.M.S.(RET.).

The present time seems particularly opportune to call atten. tion to certain aspects of the hookworm problem which threaten to cause a division of opinion and procedure among those whose common desire is its solution.

It is probably undisputed that the aggregate of ankylostome infestation is enormous, hundreds of millions of persons being infested, that the effects' of comparatively light infestations are harmful, and that an active hookworm campaign is essential. Beyond this point opinion is imperfectly orystal. lized. There is, for example, a weighty body which holds that the problem of ankylostomiasis is so great that it. must be attacked along lines admittedly unscientific and deliber. a'ely rule of thumb. Their case is a reasoned one and can be put, I think quite fairly, thus :

1. The microscope fails to detect with certainty light hookworm infestations ; so that, relying upon it, the sanitarian, intent upon producing complete disinfestation, will find nothing but disappointment.1

2. The light infestations, those with less than ten worms, missed by the microscope, do not, however, damage their host; so that the fact that the microscope misses such infestations is actually an advantage.2

3. Accordingly the right way to attack the hookworm problem in any locality where infestation is shown to be considerable is to treat all persons indiscriminately, without attempt at individual disonosis, with two treatments of oil of chenopodium 8

4. In this way 93 to 97 per cent. of the worms will be removed and all infestation material to the host will be eliminated.1 3

5. At the same time the soil will cease to be seriously infected, and reinfection of man will remain at the point where the resulting human infection will be immaterial. ${ }^{3}$

6. So that, in view of the inadequacy of microscopic diagnosis, and the practical adequacy of treatment, it is the duty of the sanitarian, faced with this huge problem, to concentrate upon the heavy cases which matter and disregard the light ones which do not.

Microscopic Detection of Ova.

Whether infestation be light or heavy, the microscopic detection of ora in the stool is manifestly impossible if the worms be not ovipositing-that is to say, if only males be present, or if the females be too young, too old, or too ill to lay. If ora be present in the stool can they infallibly be detected there by the microscope, or is it the case, as stated in the fifth annual report of the Rockefeller Foundation, International Health Board, that microscopio technique fails to detect 50 per cent. of light infestations? The answer to this lies in some sixteen months' work of mine, financed first by the International Health Board and later by the Royal Society.' This work starts from the admitted position that hookworm eggs may be so sparse in a stool that the West Indian technique is fully justified. This requires that before a negative diagnosis is made nine faecal smears on $3 \times 2$ in. 
slides, three simple and six from the deposit after centrifuging, should be examined. To save the enormous expenditure of time involved, a number of concentrative methods have been produced, designed to separate ova from faeces proper and to concentrate the former on a small area for microscopic examination. Since this work has involved the counting of over a quarter of a million hookworm eggs it rests on a foundation more solid than hitherto attempted. Since it has involved the eviction of the writer's own levita. tion technique from the premier position which he believed it to hold, the conclusious may reasonably be accepted as unbiased. Briefly the procedure has been as follows:

\section{The Standardizing Count.}

A measured quantity of stool is, by prolonged shaking with a comminutor, disintegrated into its constituent parts; it is clear that so long as faeces remain adherent to ova the ova cannot be collected apart from faeces proper. With a pipette this even faecal suspension is allocated into as many centrifuge tubes as there were cubic centimetres of original faeces. These tubes are now centrifuged for such time and at such rates as will, for the centrifuge in use, throw down all the suspended ova. In a centrifuge in which the bottom of the tube is 63 inches from the centre this will be accomplished in sixty seconds at 1,000 revolutions a minute. The supernatant fluid is decanted. The deposit in each tube, all containing on the average the same number of eggs, is treated by a different concentrative technique and the ova recovered are counted. One tube is retained as a control, in order that a coun may be made of the number of eggs with which each technique started. But since to make this count in smears in the centrifugal deposit from $1 \mathrm{cocm}$. of stool spread sufficiently thinly would occupy several hours, the eggs in a measured fraction only of the control are counted, with due precautions for the maintenance of an even suspension, and for its accurate subdivision. This number, multiplied by the fraction, gives the average ovum content per cubic centimetre.

This controlling count I have named the "standardizing count." Subjected for the first time to this rigid mathematical control, it is evident that each technique has what may be termed its "limit of effective concentration," which is to say that it will, without appreciable loss, concentrate upon a certain examination area the ova from a certain quantity of a given stool, but that if, other things being unchanged, the quantity of stool be increased or the examination area be diminished, there occurs a loss of ova, at first relative and then absolute. Methods giving on occasions brilliant results have in the past been summarily rejected because on others they have miserably failed. That failure has been due almost solely, as I believe the internal evidence demonstrates, to their having been put to do that which was quite beyond their capacity, there having been no realization-as indeed there could not be without standardization-that the limit of effective concentration was the rigidly controlling factor which these counts show it to be.

The limit of effective concentration for levitation is, at the utmost, $0.5 \mathrm{c.cm}$. of stool upon $2 \mathrm{sq}$. in. of slide, and takes from twenty to thirty minutes for complete examination. In the Kofoid and Barber and in the Willis gravity flotation methods, modified in accordance with tlie ascertained limit of effective concentration, it is 1 c.cm. of stool upon 1 to 2 sq. in. of slide, taking ten to twenty minutes for complete examina. tion. In the new centrifugal flotation method it is $1 \mathrm{~cm}$. stool upon a sixth of a square inch of slide, taking about two minutes for complete examination, while the control counts show that the number of ova lost during concen. tration by this technique is negligible. Moreover, the process of concentration is so simple that the ordinary unlettered coolie would have no difficulty in carrying out the whole of it. It seems, then, to fulfil the essentials for mass diagnosis and to combine rapidity, certainty, foolproofness, and cheapness to a degree not hitherto approached by any other technique.

This being so, does the 1 c.cm. of stool, which this technique uses, suffice for the detection of light infections? Baermann's work $^{5}$ indicates that each ankylostome female lays daily at least 1,000 eggs, or 10 ova per c.cm. in a stool of 100 grams. Darling's corresponding figures ${ }^{3}$ for each female are an average of 2,237 ova daily, with maximum and minimum figures of 7,454 and 427 .

The evidence, then, is that the properly conducted examina. tion of 1 c.cm. of stool by direct centrifugal flotation will certainly, rapidly, and cheaply detect infestations by a single, normally ovipositing, female ankylostome. In otler words, the microscope, properly used, can be relied upon to detect the lightest infections, and the statement that it misses 50 per cent. of light infections is incorrect.

'There remains, under the second heading, the question whether infections with less than ten worms do not damage their host. Evidence on this point is apparently lacking. It seems to be felt as inconceivable that a single pair of ankylo. stomes should harm their host, and this feeling is expressed, quite unjustifiably, as a direct negation. The position assumed is unsatisfying. It is that the microscope cannot detect less than ten hookworms, and that by an extraordinary coincidence it is just that number which matters. As has been pointed out, ${ }^{6}$ a similar attitude has been adopted, quite incorrectly, regarding the centrifuge, and those who now make this state. ment must surely foel under an obligation to substantiate or reject it.

It is at least certain that-there is a growing mass of evidence that the so-called carrier is improved in health and working power by disinfestation, and I know of no published evidence suggesting that there is any limit below which infestation is immaterial. Statements of personal belief on this matter appear misplaced. 'The fact seems to be that there is no satisfactory evidence either for or against the belief that the lightest infestations are immaterial to their host. With the definiteness in diagnosis which these new methods imply a few months' accurate examination in the field should suffice to settle this point and bring certainty where divergence of opinion is now expressed.

Are we justified in treating cases indiscriminately without diagnosis? In treatment we aim at employing poisons of such a nature and in such a manner that we poison all hook. worms without poisoning the host. We are only exceptionally successful in accomplishing the former, and do not always succeed in aroiding the latter. Every established line of treatment has deaths to its discredit, so that every medicel administrator who authorizes the administration of a poten. tially poisonous drug to individuals without any knowledge as to whether individually they are or are not infested inust satisfy his own conscience on the matter. But if he satisfy himself that it is ethically permissible there remains the question, Is it politic for the campaign in question? Should a death occur after anthelmintic treatment as, with unkylo. stome treatment going on upon the scale vecessary, must happen whether the drug had or had not any hand in its causation, unquestionably certain persons will say, "You have poisoned this man, and you did not even know that he was infected."

'There are yet other moral questions involved. Just as every hookworm campaign uses and benetits from advances in scientific knowledge gained by previous ones, so is there surely an obligation, for tho benetit of others, to add to that common stock of knowledge. It seems almost impossible to do so if diagnosis is to be dispensed with and treatment is to be merely by rule of thumb.

Regarding oil of chenopodium, it is true that in certain instances certain specimens bave in two treatments removed 93 to 97 per cent. of the number of worms which three treatments evacuated. There is no evidence, and indeed with the methods of diagnosis hitherto employed there could be no evidence, that 93 to 97 per cent. of all the ankylostomes originally harboured were thus remored. With knowledge of the futility of these methods it is, indeed, gravely illogical to make this assumption. Moreover, oil of chenopodium is no fixed chemical compound and has no pharmaceutical standard. The work of Caius and Mhaskar? shows that its chemical composition varies, while as regards its anthelmintic value it must not be overlooked that in the Rockefeller Foundation's Panama campaign the drug was rejected as useless. It is, then, as premature to state that two treat. ments with oil of chenopodium will evacuate 93 to 97 per cent. of all worms as that these treatments will remove all infestation which matters to the host.

Ankylostomiasis a Privy Infection.

The present conception of ankylostome infestation is that the larvae are widely disseminated in the soil; and that those who work barefooted on the soil, especially agriculturists, are particularly liable to it. Ankylostomiasis has, indeed, been definitely and unhesitatingly designated as an occupational disease. But let us consider the latest evidence. According to the experiments of Augustine ${ }^{8}$ there is practically no lateral migration of Jarvae in the soil. A circle four iuches in radius round an infected spot marks, it is said, the extreme limits of larval excursion. Unless these experiments bo disproved ankylostomiasis must be accepted as a stringently loculized ground infection, something which I would designato as a privy infection, using the term " privy " to include (1) a man-made latrine; (2) whit Cort and Payne" term a "natural 
latrine," a selected and probably sequestered spot to which an individual will constantly return; (3) what inay be designated a "casual privy," any spot whose use the call of the moment necessitates. Accepting these experiments it is impossible to admit that hookworm infection is a general infection of the soil, one which tends to evenness of diffusion; nor can one admit that it is of such a nature that the agriculturist must necessarily meet wandering larvae in the course of his work. Were this so, however, we could agree with those who clearly look upon the soil as one uniform whole more or less uniformly infected, and maintain that the amount of soil in!ection generaliy, and the consequent risk to those who work on it, must be proportionate to the number of ova which fall upon it-that is, to the number of ankylo. stomes harboured by the inhabitants. On such grounds, too, one would have to agree with Darling ${ }^{3}$ that, could one reduce the number of ankylostomes to a certain level, one would reduce the larvae they breed to a point where human infection would be slight, and, if one be willing to concede this without proof, negligible; and that no increase in the infection rate of a community could occur without importation of a heavier infection from outside.

But, on the contrary, the evidence of Augustine's experiments is that infection must be constantly, presumably preponderatingly, a "privy" infection, and that in the case of man-made latrines and "natural latrines" it is what $I$ have termed a dejectional infection ${ }^{10}$-obtained, that is, at the time of defaecation. Only in case of his skin coming into contact with ground which has been used as a casual privy will an individual acquire what $I$ have termed a casual infection ${ }^{10}$; and that will generally be but seldom.

If, then, one conclude - and it is difficult to escape doing so - tlat recent evidence points to hookworm infection as being uudéfordinary conditions practically always a privy infection, and preponderatingly a dejectional infection, one is confronted with this question: Does the man-made latrine, as recom. mended by the sanitarian, prevent infection; or does it actively disseminate it? There will scarcely be opposition to the statement that ankylostome infestation cannot occur from a clean sewered water-closet, whence the infected stool is at once removed. But in those widely ased, because widely recommended, latrines where the stools are dealt with in situ with a view to larval destruction, the position is unsatisfactory and disquieting. McVail ${ }^{11}$ has found that ova and larvae, identified as those of hookworms, are constantly present in the effluent of those fine septic tanks which stand on the banks of the Hugli; Minett ${ }^{12}$ and Khalil ${ }^{13}$ have found them similarly in the West Indies; Khalil14 quotes experiments to show that these larvae can swim; Payne ${ }^{15}$ has shown that even if larvae do not migrate laterally on the surface of the ground; they can mount vertically through at least 36 inches of soil. Accordingly any latrine which permits of direct or indirect pollution of the soil or subsoil is, under present conditions, unsafe.

Since, apart from sewered latrines, there are such grave reasons for suspecting all man-made latrines as disseminators of hookworm infection, it is pertinent to inquire the extent to which a man, conscientiously using his privy and harbouring but a single pair of ankylostomes, will infect that privy. The answer lies in the work of Baermann and of Darling, to which reference hias been made above. Assuming for the sale of even numbers that this particular pair of worms produced 2,740 fertile eggs daily, the number deposited in the latrine will be a.million a year. We are assured that nine ankylo. stomes, or four to five million eggs a year, are hygienically negligible. It is not unreasonable to ask of those who are maintaining that this prodigious figure is hygienically negligible that they should either prove it or cease to urge it as a working hypothesis. There is an unfortunate disposition to take sides on this matter, and as one who is credited with leading the opinion that all infection matters ${ }^{2} I$ would suggest that it is immaterial what anyone's opinion is, except in so far as it acts as a spur to the collection of facts. What is required is fact, and pending the collection of further facts there seems ample justification for the refusal to accept as personally or hygienically negligible any infection however slight.

\section{The Needs of Hookworm Campaigns.}

Seeing, then, that, by the evidence, accurate microscopic diagnosis is a reality; that treatment does not produce effective disinfestation; and that ankylostomiasis must, on our present evidence, be looked upon as, in the main, a privy disease, and not a general soil disease; the case which has been stated, and as I believe fairly stated, above collapses.

The problem is really a somewhat pathetic one. In the face of an urgent situation hookworm caimpaigns have been pushed forward. Certainly something had to be done; but the results are in certain respects deplorable. Promises haves been rashly made which have not been; and could not be, substantiated, because the premisses on which the argument for their validity rested were unsound.

The present position would seem to be fairly stated thus: Diagnosis, thanks largely to the recognition of the principle of the limit of effective concentration, has now been placed in such a position that it will cheaply, certainly, and rapidly detect hookworm infection, provided normal oviposition proceed. Treatment and prevention lag far behind. We need a drug which will disinfest certainly, preferably in one treatment. Why should we rest content to say, as is said, that certain and complete disinfestation is impossible of attainment? 'The acceptance of defeat in the situation is unthinkable. We need a latrine, simple, cheap, protitable, foolproof, suitable for the poor hut dweller. We have no approach to it, nor are we likely to have so long as there is no active dissatisfaction with, no strenuous striving to better. what we have. We need properly financed research to solve these and like urgent and vital problems in ankylostomiasis. We need research in order to avoid the heavy waste of money which has occurred so strikingly in the past in hookworm campaigns; for most of the work which has been done will have to be done again. Money spent in adequate research will come back multiplied many fold, not only in the capacity for work and earniug, but in that measure of health, happiness, and length of life which our national commitments make it incumbent that we should at jeast offer to those backward races for whom we have made ourselves responsible.

REFERENCES.

Darling. S. T., and Smillie, W. G.: Studies on Hookworm Infection in Brazil, frrst piper, Mon. Rockefeller Inst. Med. Res., No. 14, 192

Studies in Hoolsworm Infection in Brozil, second paper, Mon. Rockifeller Inst. Med. Res., 17, 1922.

8 Darling, S. T.: The Hookworm Index and Mass Treatment, Amer. Journ. 'Trop. Med., vol. 2, p. 397, 1922

4 Lane, Clay ton: Mass Diagnosis in Ankylostome Infestation, Fart I. Trans. Roy. Soc. Trop. Med. and Hyg., vol. 16, p. 274 (1922), 1923.

5 Baermann, G. : Ueber Ankylostomiasis deren Ausbreitungs bedingungen durch die Bodeninfektion und deren Bakaempfung, Geneesk. Tijdschr. $v$. Nederl.-Indie, vol. 57, p. 574, 1917

6 Lane, Clayton: Final Report on the Ankylostome Inquiry in the Darjeeling District of Iudia, Indian Journ. Med. Res., vol. 5, p. 350, 1917 . 7 Caius, J. F., And Mhaskar, K. S.: The Correlation between the Chemical Composition of Anthelmintics and their Therapeutic Values in Courn. Med. Res., vol. 7, p. 570, 1920

Journ. Med. Res., vol. 7, D. 570, 1920. VIII, Amer. Journ. of Hyg., vol. 2, p. 162, 1922.

9 Cort, William W., and Payne, George C.: Ibid., VII, Amer, Jouru. of Hya., vol. 2, p. 149, 1922.

Journ. Med. Res., vol. $7, p .23$.

Preliminary Not3 on Septic Tank Latrines in Relatic

12 Minett, E. P. A Cheap Type of School Latrine for Country Districts in the Tropics, in Relation to Ankylos tomiasis and other Diseases, Trans. Roy. Soc. Trop. Med. and Hyg., vol. 16, p. 119, 19/2.

13 Khalil, M.: On the Septic Tank in the Tropics: from a Helminthological Standpoint. Report of the West Indian Medical Conference, 1921. 14 Khalil, M. : Thermotropism in Ankylo : tome Larvae, Proc. Roy. Soc. Med. (Sec. Trop. Dis. and Parasit.), vol. 15, No. 4, p. 16, 1922.

15 Payne. Florence K.: Investigations on the Control of Hookworm Disease, xiv, Amer. Journ. of Hyg., vol. 3, p. 46.

\section{THE INFLUENCE OF IN'TESTINAL BACTERIA UPON THE THYROID GLAND.}

BY

D. J. HARRIES, M.D., D.Sc., B.S., F.R.C.S., SORGEON, CITY LODGE HOSPITAL, CARDIFF ; ASSISTANT 8URGEON, KIYG GDWARD VII HOSPITAL, CARDIFF.

Severac years ago Sir Arbuthnot Lane suggested that exophthalmic goitre was produced by the toxins absorbed from the alimentary canal in intestinal stasis, and advocated colectomy as one of the methods of treatment. As a result of several years of study of the diseases of the thyroid gland I have arrived at the conclusion that his suggestion regarding the etiology of the disease was nearer the truth than most people thought at the time. His suggested method of treating the disease has not been widely adopted.

To appreciate the conclusions I have arrived at it is neces. sary to consider some factors arising out of the metabolism of certain proteins; these factors bear an intimate relation to the causation of diseases of the thyroid gland. 